\title{
Urinary Tract Fistula
}

National Cancer Institute

\section{Source}

National Cancer Institute. Urinary Tract Fistula. NCI Thesaurus. Code C79850.

An abnormal communication between any part of the urinary system and another organ or cavity. 